\title{
RADICALIZACIÓN POLÍTICA Y REPRESIÓN ESTATAL: LA JUVENTUD OBRERA Y UNIVERSITARIA ANTE LA REVOLUCIÓN CUBANA Y EL PLAN CONINTES. EL CASO DE LA CIUDAD DE LA PLATA, ARGENTINA (1959-1962)
}

\author{
Political Radicalization and State Repression: Working and University Youth \\ During the Cuban Revolution and the CONINTES Plan. The Case of La Plata, \\ Argentina (1959-1962)
}

\author{
Nayla Pis Diez * \\ http://orcid.org/0000-0003-2914-828X
}

Horacio Robles **

http://orcid.org/0000-0001-9229-5886

\section{Resumen}

Ubicados en los tempranos años sesenta, este artículo se propone reconstruir una parte de la historia política de la juventud argentina, en particular, de la ciudad de La Plata, a través de dos procesos: primero, el impacto de la Revolución Cubana y la radicalización de las organizaciones de izquierda y peronistas; segundo, la proliferación del anticomunismo, la extensión y transformación de las prácticas represivas gubernamentales con efecto directo sobre la vida de aquellas organizaciones. Nuestro objetivo es analizar aquellas transformaciones políticas tan típicas de los años sesenta tomando como caso la militancia joven de la ciudad, la trabajadora e identificada con el peronismo, y la estudiantil, identificada al mismo tiempo con la Reforma Universitaria y diversas organizaciones de izquierda. La "juventud" como concepto y lo "local" como escala de análisis son además, las claves metodológicas de este trabajo.

$<$ Juventud $><$ Peronismo $><$ Movimiento Estudiantil $><$ Comunismo y Anticomunismo $>$

\begin{abstract}
This article aims to reconstruct a part of the political history of Argentinian youth, particularly in the city of La Plata in the 1960s. This will be done through a dual approach: first, by analyzing the impact of the Cuban Revolution and the radicalization of the leftist and Peronist organizations; second, by discussing the proliferation of anti-communism and the extent and transformation of the government's forms of repression, which had a direct effect on the organizations' practices. Our aim is to analyze the political transformations that were typical of the sixties, focusing in particular on the city's young activists, the workers, who were identified politically with Peronism, students advocating for University Reformism, and diverse leftist organizations. In our methodology, we use youth as a key concept and focus on the local as the scope of our analysis.

$<$ Youth $><$ Peronism $><$ Student Movement $><$ Comunism and Anti-communism $>$

Recibido: 25/04/2019

Aceptado: 23/07/2019

\footnotetext{
* Instituto de Investigaciones en Humanidades y Ciencias de la Educación. Universidad Nacional de La Plata. Comisión Nacional de Investigaciones Científicas y Técnicas (CONICET). La Plata, Argentina. nayla.pdiez@gmail.com

** Instituto de Investigaciones en Humanidades y Ciencias de la Educación. Universidad Nacional de La Plata. La Plata, Argentina. hrobles1957@hotmail.com.ar
} 
Pis Diez y Robles. Radicalización política y represión estatal: la juventud obrera y universitaria ante la Revolución...

\section{Introducción}

Este trabajo se propone reconstruir una parte de la historia política de la juventud militante de los años sesenta en Argentina, en particular, de la ciudad de La Plata, capital de la Provincia de Buenos Aires. En términos temporales, nos situamos en una etapa de muchas convulsiones políticas. En septiembre de 1955, un golpe de Estado autodenominado "Revolución Libertadora" derrocó al gobierno de Juan D. Perón, persiguió a sus referentes y militantes e inició una etapa marcada por la proscripción política y electoral del peronismo que, con breves y controvertidas excepciones, se mantuvo hasta 1973. Por ello, los años que siguen a 1955 son denominados como la Resistencia Peronista, protagonizada por el sector obrero y sindical. Al mismo tiempo, una parte de los actores políticos que apoyaron la maniobra militar de 1955 comenzaron a tomar distancia de las posturas iniciales. Esto es, fracciones de partidos políticos tradicionales, de intelectuales, universitarios y de la izquierda, se alejaron del "antiperonismo" radical e iniciaron nuevas experiencias políticas. Una de ellas, fue la protagonizada por el luego presidente Arturo Frondizi (1958-1962), figura que concentró las críticas hacia el gobierno militar con una propuesta económica desarrollista, nacionalista e "integracionista" hacia el peronismo. Al poco tiempo, no obstante y como veremos, ese programa acabó en "traición”.

Ubicados en los tempranos sesenta, nos enfocamos en dos procesos que marcaron aquellos años: primero, el efecto de la Revolución Cubana sobre las organizaciones de izquierda y peronistas; segundo, la proliferación del anticomunismo, la extensión y transformación de las prácticas represivas gubernamentales que impactaron directamente en la vida de aquellas organizaciones. Nuestro objetivo es analizar aquellas transformaciones políticas tan típicas de los años sesenta tomando como caso la militancia joven de la ciudad, la trabajadora e identificada con el peronismo, y la estudiantil, identificada al mismo tiempo con la Reforma Universitaria y diversas organizaciones de izquierda. Desde aquí, nuestro análisis estará centrado en dos actores centrales del escenario platense de esos años: la Juventud Peronista (JP), que se reorganiza en la ciudad pasado el golpe militar de 1955; y el movimiento estudiantil reformista, la Federación Universitaria de La Plata (FULP) y agrupaciones de varias facultades. Si en 1955 un abismo social y político las separaba, a partir de 1959 las cosas comenzaron a cambiar como consecuencia de diversos acontecimientos. Como se sugiere, organizamos la exposición a partir de dos perspectivas: la "juventud" como concepto y lo "local" como escala de análisis. Creemos que ambas nos permiten una lectura sobre la historia reciente argentina basada en la reconstrucción de procesos tempranos de radicalización política en la juventud y acercamientos entre tradiciones políticas y culturales las más de las veces distantes entre sí, el reformismo universitario y el peronismo.

En cuanto al concepto de juventud, cabe introducir algunos elementos. Primero, es ya reconocido que constituye un concepto que nos ayuda a pensar y comprender los años cincuenta y sesenta, aunque no se circunscribe a ellos. En el campo de estudios sobre el tema, diversos trabajos de referencia proponen no acotar su surgimiento y desarrollo a la segunda mitad del siglo XX, sino ubicar tales fenómenos en los 
comienzos del siglo XIX y más aún, su consolidación en el período de entreguerras europeo, cuando se produjo la primera gran oleada de movilización juvenil en dicho continente (Souto Kustrín, 2007). ${ }^{1}$ En este marco, las décadas de 1950/1970 no habrían significado el abrupto surgimiento del sujeto joven sino más bien los años de mayor visibilidad política del mismo. Y aunque, como sostienen Bettina Favero y Mónica Bartolucci (2018), no debemos confundir a los "jóvenes rebeldes y modernos" con la experiencia de toda una franja etaria, sí cabe decir que aquellas décadas nos muestran a la juventud como protagonista y portadora de todo un conjunto de transformaciones políticas, sociales y culturales que marcaron, al menos, a las sociedades occidentales. Podemos decir que, con una periodización más marcada por ciclos políticos propios que por las guerras europeas, nuestro país no fue una excepción. Tempranamente, Juan Carlos Torre (1994) escribió un artículo rememorando las insurrecciones de 1969, en las que se condensaron varias historias: una de ellas, la de la juventud, constituida en actor político y colectivo desde los años cincuenta, aunque también, desde entonces, "extrañada" y ajena a un sistema político ilegítimo. Para Valeria Manzano (2017), la verdadera "era de la juventud" en Argentina comenzó en los años cincuenta, con características transnacionales pero anclada en dinámicas políticas y sociales nacionales. Para ella, son tres los puntos de inflexión que marcan el advenimiento de la "juventud" en este país: los debates en torno a la organización de estudiantes secundarios y jóvenes durante el peronismo (entendidas como espacios de "corrupción moral"); la aparición de nuevas profesiones, como psicología y sociología, que comenzaron a asociar el término a los de crisis y rebeldía; y el imaginario (presente, sobre todo, en el campo político e intelectual, en importantes partidos como el Radical y el Socialista y en revistas como Contorno) de una generación actuante en política pero frustrada por sus "maestros" y referentes adultos a comienzos de 1960. De esta manera, mujeres y varones jóvenes, de estratos medios y obreros, fueron portadores de los aspectos más significativos

\footnotetext{
1 La española Sandra Souto Kustrin define a la juventud de la siguiente manera: "Como etapa de transición de la dependencia infantil a la autonomía adulta, se define por las consideraciones que la sociedad mantiene sobre ella: qué se le permite hacer, qué se le prohíbe, o a qué se le obliga. Se espera que los jóvenes empiecen a diseñar un currículo de decisiones propias - amigos, ocio, colectivos a los que se quiere pertenecer, educación, mercado laboral - que los convierta en sujetos autónomos (...) Entre los factores que favorecieron el desarrollo de la juventud como un grupo de edad claramente definido destacan la regulación del acceso al mercado laboral y de las condiciones de trabajo de niños y adolescentes; el establecimiento de un periodo de educación obligatoria que se fue ampliando con el paso del tiempo y que se hizo cada vez más importante para asegurar el acceso al trabajo y el mantenimiento del estatus social (...)" (Souto Kustrin, 2007, pp. 171-173). En su clásico trabajo, Eric Hobsbawm señala que una de las revoluciones sociales más importantes de la segunda mitad del siglo XX fue la irrupción de una "cultura juvenil" masiva e internacionalizada: "Los jóvenes, en tanto que grupo con conciencia propia (...) se convirtieron ahora en un grupo social independiente. Los acontecimientos más espectaculares, sobre todo de los años sesenta y setenta, fueron las movilizaciones de sectores generacionales (...) La radicalización política de los años sesenta (...) perteneció a los jóvenes.” (Hobsbawm, 2006, p. 326). El autor reconoce que la conformación de la "juventud" no fue una novedad de ese tiempo, aunque, en la segunda mitad del siglo XX esta tuvo tres características: no era vista como una fase "preparatoria" sino como una de plenitud de la vida; en tanto consumidores y productores, fueron un sujeto clave para las economías del mundo capitalista; era internacionalizada.
} 
Pis Diez y Robles. Radicalización política y represión estatal: la juventud obrera y universitaria ante la Revolución...

de la modernización social, cultural y sexual; al tiempo que expresaron las tensiones emanadas de tales cambios, bajo la forma de rebelión cultural y radicalización política.

Si bien lo anterior sirve para pensar los rasgos generales del fenómeno, es importante no homogeneizar a la "juventud" y considerar sus anclajes de clase y de género así como sus tradiciones organizativas y espacios de pertenencias. Esta advertencia sirve en particular para nuestro trabajo, pues nos guía el intento de abordar el caso de la juventud platense obrera y estudiantil, esto significa, un colectivo juvenil con pertenencias de clase distintas que, por ello, atravesaban espacios urbanos a veces excluyentes entre sí (la universidad, los sindicatos, las fábricas). También, con tradiciones políticas y culturales heterogéneas aunque más coincidentes en el momento histórico que vamos a trabajar. Es que, de antemano sabemos que la Revolución Cubana impactó con fuerza tanto en los jóvenes universitarios como en aquellos militantes de la izquierda y el peronismo de la resistencia. Pero, en sí misma, poco nos dice la edad de los protagonistas sobre tal impacto. Es por ello que aquí buscamos otorgarle densidad considerando, como decíamos, la pertenencia de clase, los espacios organizativos y las tradiciones políticas. ${ }^{2}$ Como opción metodológica, vamos a considerar tales variables desde un enfoque local. Lejos de generalizaciones amplias, buscamos "achicar el foco" (Aguila, 2015) y centrarnos en las particularidades del caso platense, para así, contraponer elementos que otorguen densidad, mayores grados de complejidad, diferencias y novedades a las explicaciones generales sobre el período. ${ }^{3}$

Una idea-fuerza que guía el trabajo consiste en afirmar que a partir del año 1959, militantes juveniles que provenían de tradiciones políticas distantes, transitaron un proceso de cambio. Dicho proceso tomó forma a partir del impacto de la Revolución Cubana, por un lado; y, por otro, de los cambios en la política represiva del gobierno de Arturo Frondizi, uno que en principio se apoyaba. Bajo esa dinámica, los y las jóvenes platenses formaron parte de una amplia red de actores locales y nacionales

2 Coincidimos aquí con Souto Kustrín (2007) en que "la juventud" poco depende de la edad, sino que es más bien una construcción con ciertas coordenadas históricas y sociales; una construcción que debe entenderse siempre en su contexto, dentro del orden económico, social, cultural y político de cada sociedad y de cómo dicho sujeto es definido por ese orden. Pero además, importa considerar cómo dicho sujeto se definió en cada época a sí mismo, cómo la juventud se ha identificado como tal y mediante qué tradiciones lo ha hecho. En la historia de nuestro país, dos tradiciones han sido fundamentales para dar forma a "la juventud", con espacios propios, una identidad y objetivos políticos que ordenaban su actuación: el reformismo universitario, inaugurado en 1918 y marcando a generaciones de universitarios desde entonces; y el peronismo, para el período que va de 1950 a 1970, aunque particularmente los primeros años de esta última década.

3 Seguimos aquí a Gabriela Aguila (2015) cuando afirma que en el campo de la historia reciente argentina han primado las miradas "amplias y nacionales", es decir, trabajos de análisis pioneros y generales pero con explicaciones basadas en un caso (el de Buenos Aires) y generalizadas; por ejemplo los clásicos trabajos de Silvia Sigal (1991) y Oscar Terán (1991). Y aunque en la última década esto se ha revertido, continúa siendo un desafío para la historiografía argentina descentrar la mirada respecto de Buenos Aires, o al menos, no tomarlo como el todo (Leoni, 2013). Este aspecto es importante pues, entendemos con Sandra Fernández (2007), que "lo local" no dice nada por sí mismo, sino que es tarea de quien investiga otorgarle valor explicativo. Aquí no buscamos construir una "historia en pequeño" o una historia "en la ciudad" sino más bien contribuir, con elementos novedosos, a explicar un problema más general del período como es la radicalización de la juventud militante de los años sesenta. 
que si bien atravesó un momento de "repliegue" (producto de la relativa eficacia del plan represivo), al mismo tiempo, desarrolló un proceso de mutuo acercamiento y apertura, iniciando novedosas experiencias políticas que jalonarían los años inmediatos. Bajo estas premisas el trabajo se organiza en tres apartados. El primero consta de una presentación de los actores teniendo en cuenta sus formas organizativas, sus prácticas políticas y sus espacios de actuación. El segundo aborda la recepción temprana de la Revolución Cubana, sus matices y los procesos de radicalización que aparejó. El tercero se ocupa del impacto que tuvieron las políticas represivas del gobierno de Arturo Frondizi, en aquella clave de "repliegue" y "apertura" al mismo tiempo: pues si bien, la represión anticomunista y antiperonista se lanzó sobre buena parte de las experiencias pro cubanas y de lucha sindical, generó también nuevas condiciones de acercamiento entre los jóvenes universitarios y los peronistas, ambos ubicados en el campo de una izquierda que empezaba a modificar sus fronteras.

Finalmente, resta decir que este trabajo encuentra un cimiento fundamental en las fuentes orales y en la documentación escrita utilizada. Las primeras son entrevistas de autoría propia y testimonios ya publicados por los protagonistas o en compilaciones amplias. En el segundo caso, particularmente, han sido de enorme utilidad registros de diarios locales, (El Argentino y El Día) con detallada y abundante información sobre la Universidad y la ciudad. También ha sido fundamental el acceso a los documentos de espionaje elaborados por la Dirección de Inteligencia de la Policía de Buenos Aires (DIPBA) y hoy desclasificados por la Comisión por la Memoria (CPM).

\section{Los actores y la ciudad}

En La Plata, la diversidad de espacios estudiantiles era inmensa y abarcaba varios planos de la vida social juvenil. En una dimensión más bien gremial y política nos encontramos con la conocida FULP creada en 1911, con un fuerte protagonismo político desde 1918-1919, al igual que sus respectivos Centros de Estudiantes por facultad. La ciudad de La Plata es una que siempre se ha caracterizado por recibir importantes contingentes de estudiantes de otras ciudades y provincias, como también de otros países. Por ello, cabe una mención a los ámbitos constituidos por los universitarios no platenses, la Federación de Universitarios del Interior y los Centros de Estudiantes de países latinoamericanos, como los de Bolivia, Venezuela, Colombia y Perú. Tanto la FULP, los Centros de Estudiantes clásicos o los agrupados por procedencia geográfica, reconocían la Reforma Universitaria como el marco de principios orientador aunque esto no significara homogeneidad interna, más bien al contrario. Una línea de demarcación propia del reformismo universitario está dada por las adscripciones políticas y/o partidarias de las agrupaciones estudiantiles y las referencias que las integraban. Existían, por ejemplo, agrupaciones más ligadas al Partido Comunista (PC), otras a la Unión Cívica Radical (UCR), al Partido Socialista (PS) o al anarquismo. El mapa universitario se ordenaba, no solo bajo el eje reformismo/antirreformismo, sino también a partir de lineamientos políticos que definían corrientes reformistas adversarias. En Argentina, buena parte del debate del período no se comprende sin hacer mención al eje peronismo/ 
Pis Diez y Robles. Radicalización política y represión estatal: la juventud obrera y universitaria ante la Revolución...

antiperonismo que dividió aguas en todo el escenario social, político, intelectual y profesional. En el campo de estudios sobre universidades argentinas, se coincide en afirmar que a partir de septiembre de 1955 se abrió en tales instituciones un proceso de intervención que se caracterizó por dos tendencias principales: la "desperonización" como proyecto político, es decir, la exclusión de todo individuo, símbolo o normativa identificada con el peronismo; y un plan de gestión basado en la "modernización" académica y científica que, con el correr de los años, se enfrentaría a diversas tensiones, conflictos y debates, sobre todo con los estudiantes reformistas (Buchbinder, 2005; Sigal, 1991). Conflictos como los referidos a la creación de universidades privadas habilitadas para emitir títulos en 1958, o los relativos a la aceptación de fondos norteamericanos para las universidades públicas en 1959/1960, fueron creando hondas grietas entre los reformistas, entre los profesores, autoridades y estudiantes y al interior mismo de las organizaciones estudiantiles. Por esto, en los años que aquí trabajaremos, identificamos dos corrientes universitarias reformistas, una primera que denominamos de izquierdas, integrada por espacios como el PC, ramas del PS, el trotskismo y la "nueva izquierda". Esta combinaba una postura latinoamericanista, anti estadounidense, con posiciones alejadas del antiperonismo que hacía poco más de una década había caracterizado al movimiento universitario. Por otra parte, la corriente reformista que denominamos tradicional o "democrática" mantenía una férrea posición anticomunista (y crítica de la Unión Soviética) y antiperonista; combinadas ambas cuestiones con un intento de priorizar el aspecto gremial, o no político-partidario, en sus intervenciones en la Universidad. Como podemos suponer, a partir de 1959, pero sobre todo desde 1961, la cuestión cubana no hizo más que ahondar aquellas diferencias.

La etapa abierta tras 1955 fue vivida de forma muy distinta por la juventud trabajadora e identificada con el peronismo. Primero, luego de la proscripción de ese año, la JP fue refundada en la ciudad de La Plata bajo un espíritu de fuerte crítica hacia la dirigencia política y sindical del peronismo, la misma que a su entender se habría mostrado impotente y claudicante frente al derrocamiento de 1955. Esta evaluación llevó a la agrupación juvenil a autoproclamarse como generación "vanguardia" del proceso de restitución del "gobierno popular", esto es, de la Resistencia Peronista en la ciudad. Bajo esas premisas políticas, hacia finales de 1957, la JP se constituyó al amparo de la paulatina reactivación sindical local aunque manteniéndose en la clandestinidad. Sus miembros más importantes eran trabajadores y dirigentes reconocidos de entidades gremiales ya oficializadas, es decir, ahora reconocidas por el gobierno, como la Asociación de Trabajadores del Estado (ATE). ${ }^{4}$ Por otro parte, gracias a su capacidad de trabajo y un número importante de 70 miembros con absoluta mayoría de trabajadores, la JP logró un rápido reconocimiento en seno del peronismo local, organizando actos multitudinarios en la ciudad, impulsando las tareas partidarias de afiliación, electorales y conmemorativas, cuando las condiciones de la proscripción lo permitían. En paralelo

${ }^{4}$ Una parte importante de los gremios conducidos por peronistas, e incluso la Confederación General del Trabajo (CGT), fueron intervenidos luego de 1955. En 1957 comenzó el proceso de "normalización" y en agosto de 1957, fue normalizada la CGT platense con una hegemonía de dirigentes peronistas, seguidos de independientes y comunistas (Raimundo, 2014). 
a este activismo legal, muchos de los miembros dirigenciales de la JP tuvieron un papel central en los llamados Comandos de la Resistencia, organizaciones creadas por peronistas en todo el país, que se caracterizaban por protestar contra la Revolución Libertadora con prácticas de "guerrilla urbana". 5

Bajo esa doble dinámica, de inserción sindical y radicalidad política en las calles, la JP se convirtió en actor ineludible de la ciudad, interactuando con diversos actores relevantes. En primer lugar, las reuniones y plenarios de la CGT local. Eran estos espacios de discusión para definir estrategias sindicales ante las políticas represivas de los gobiernos de la "Revolución Libertadora" (1955-1958) y A. Frondizi (1958-1962). Esto supuso un importante intercambio de los jóvenes peronistas platenses, no exento de fuertes enfrentamientos, con delegados de gremios alineados con el Partido Comunista, Socialista y los grupos trotskistas de Palabra Obrera. En segundo lugar, otro interlocutor central de la JP fue la Iglesia Católica. Si en la etapa previa al golpe de Estado de 1955, la relación entre el peronismo y la Iglesia había sido de enfrentamiento, esto cambió con el correr de la década de 1950. En ese marco, la JP se apoyó en la jerarquía católica local para legitimar sus actos conmemorativos a través de los oficios religiosos; obtener ayuda para la liberación de sus presos o ligarse con la incipiente militancia popular de los sacerdotes barriales como Pascual Ruberto, sacerdote obrero y peronista de la localidad de Berisso que no ahorraba palabras para criticar a los estudiantes universitarios y a los partidos antiperonistas en los diarios de la ciudad.

Podemos concluir que la trayectoria de la JP en este período fundacional tuvo una doble dimensión política: por un lado, de inserción en los espacios sindicales, partidarios y católicos de la ciudad; por otro, de lucha y acción directa en las calles. Este último aspecto, fue dándole al grupo juvenil una fuerte impronta de radicalidad que lo distanciaba de otros sectores del heterogéneo movimiento peronista. Sus acciones en el frente obrero y los gremios que conducía; el protagonismo frente a la ocupación de dependencias estatales; los piquetes de huelga y colocación de artefactos explosivos en algunas pequeñas fábricas locales, los mostraban como uno de los grupos más activo de la Resistencia en la ciudad. Desde esta radicalidad, los jóvenes peronistas también fueron interpelados por las iniciativas políticas generadas, entre otros hechos, por la Revolución Cubana e impulsadas por el otro actor central de la ciudad universitaria: el movimiento estudiantil y sus corrientes reformistas de izquierdas. La forma como impacto tal acontecimiento en nuestros grupos, estudiantiles y obreros, no hace más que completar la breve caracterización aquí realizada.

\footnotetext{
5 De acuerdo a "Babi" Práxedes Molina, miembro fundador de la JP e importante militante del peronismo platense, la situación era la siguiente: "Todo desde ese grupo clandestino de la JP que éramos alrededor de 70 y pico de compañeros. Un número muy importante. Había dos o tres compañeros que venían de una actuación de la JP anterior, los demás sin experiencia previa [...] Universitarios había 3 o 4. Nos cobijamos en el local recuperado de la CGT, porque el partido estaba intervenido. No existía, no había locales. Había dirigentes del partido que fueron diputados, pero nadie tenía nada". Entrevista a Molina, Práxedes "Babi" por el autor, La Plata, junio de 2005.
} 
Pis Diez y Robles. Radicalización política y represión estatal: la juventud obrera y universitaria ante la Revolución...

\section{Cuba, comunismo y tercermundismo: dos formas de recepción temprana}

Como bien ha dicho Oscar Terán (2014), no hay que exagerar sobre el impacto inicial que el ingreso de las columnas guerrilleras a La Habana ejerció tanto para las derechas como para las izquierdas del continente. En Argentina, durante su primer año, la gesta revolucionaria fue apoyada por la gran mayoría del arco político, la prensa y los grupos de intelectuales liberales. Hasta comienzos de 1960, el proceso caribeño se mantuvo en una orientación más bien democrática o antidictatorial, en cuyo apoyo coincidían liberales, nacionalistas y socialistas. En la universidad, en principio, el entusiasmo fue común a estudiantes, profesores, reformistas, liberales, comunistas y anarquistas. Luego, el apoyo a una Cuba cada vez más enfrentada con los Estados Unidos se convirtió en una bandera que separó al reformismo de izquierdas de los restantes actores ya críticos del proceso caribeño. En el ámbito del peronismo, también hubo desplazamientos aunque en un sentido contrario. Es que aquella caracterización inicial era también asociada al movimiento militar que, en 1955, derrocó al gobierno de Juan D. Perón; por ende, fue observada con sospecha en este mundo. Más tarde, los alineamientos de la isla lograron que una parte del movimiento peronista, sobre todo la joven y de izquierda, comenzara a ver allí un faro y un ejemplo. Claro que no fue este un cambio automático. La gesta cubana fue siempre observada con lente nacional y por ello, no siempre celebrada.

El apoyo de los universitarios reformistas de La Plata a los revolucionarios cubanos no comenzó en enero de 1959. Como se ha mostrado, por ejemplo para la ciudad de Buenos Aires (Califa, 2014), estudiantes y profesores apoyaron con fuerza la lucha del Movimiento Revolucionario 26 de Julio prácticamente desde sus inicios. En nuestra ciudad, ya en marzo de 1957, el repudio al asesinato del dirigente universitario José Antonio Echeverría fue generalizado entre los organismos estudiantiles, las autoridades y los partidos de izquierda, tomando la forma incluso de huelga estudiantil. En agosto de 1958, impulsado por cubanos como Jorge Valdés Miranda, se constituyó una filial platense del Movimiento Revolucionario 26 de Julio similar a la que existía en Buenos Aires desde el año anterior. Pasados los primeros días de enero de 1959, la FULP hizo público su apoyo a la triunfante Revolución colocándola en estrecha sintonía con el espíritu de la Reforma Universitaria: "La Reforma universitaria gana hoy en Cuba una gran batalla. Puesto que ve hermanados en fuerza común a los obreros y estudiantes cubanos en un mismo anhelo de libertad". ${ }^{6}$ Por entonces, el apoyo a Cuba, traducido en una suerte de optimismo antidictatorial, no iba a generar grandes debates en la comunidad universitaria. Más aún, en julio de 1959, el Consejo Superior de la UNLP aprobó una declaración de solidaridad con el gobierno cubano y el Movimiento 26 de Julio, considerado este un "símbolo de rebelión legitimada"?

Como sugerimos al comienzo, el hecho de que la Revolución Cubana haya sido recibida sin demasiado temor por el establishment y el heterogéneo arco político

6 "Declaración de FULP", El Argentino, 6 de enero de 1959, La Plata.

7 La declaración fue realizada por el anarquista José María Lunazzi, profesor consejero por la Facultad de Humanidades y aprobada por unanimidad en el Consejo. Actas Taquigráficas del Honorable Consejo Superior de la UNLP. “Acta N 729”, 22 de julio de 1959, La Plata, p. 7. 
argentino, encuentra razón en los paralelos trazados con septiembre de 1955. El triunfo sobre la dictadura de Fulgencio Batista fue interpretado como un "episodio regenerador de la política", asimilado al derrocamiento de Juan D. Perón (Bozza, 2016, p. 4). Pero en pocos meses, la radicalización de los hechos en la isla definió nuevas posiciones y la "cuestión cubana" quedó colocada como centro latinoamericano del enfrentamiento entre Estados Unidos y la Unión Soviética. Para mediados de 1960, el "peligro comunista" ya estaba instalado en la prensa liberal y conservadora: Cuba pasó a significar la posibilidad de concreción de un proyecto socialista en el continente. ${ }^{8} \mathrm{~A}$ partir de aquí la Guerra Fría, "sus presiones, sus temas y sus obsesiones, se instalaron de lleno en la Argentina" (Altamirano, 2001, p. 74), en sus medios de comunicación, en su campo político y en sus Fuerzas Armadas, definiéndose las posiciones ideológicas casi exclusivamente a partir de la dicotomía comunismo/anticomunismo. En nuestro país además, aquel par se iba a cruzar con el omnipresente peronismo/antiperonismo, modificando no pocas identidades y posiciones.

En cuanto a los jóvenes peronistas, la recepción del proceso cubano los colocó ante la urgencia de establecer posiciones que fueran más allá del par peronismo/ antiperonismo y del rechazo típico de su espacio a todo lo que tuviera sabor a comunista. De acuerdo con los testimonios, los jóvenes comenzaron a ver que las herramientas teórico-políticas con las que contaban debían ser revisadas para poder procesar la nueva y disruptiva realidad regional. ${ }^{9} \mathrm{Al}$ poco tiempo, las analogías mecánicas comenzaron a desecharse y el 1959 cubano se diferenció cada vez más del 1955 argentino. Los actores conservadores, liberales y antiperonistas del arco político comenzaron a enunciar con mayor claridad su oposición al rumbo que estaba adquiriendo el proceso cubano. De esta manera, la analogía con 1955 dejó de funcionar y una parte de los jóvenes peronistas comenzó a advertir que "sus enemigos" eran también los de Cuba. Por otro lado, un referente del peronismo revolucionario como John W. Cooke residía en Cuba desde los primeros meses de 1959, manteniendo un profuso intercambio con Juan D. Perón sobre el proceso de la isla y la importancia de prestarle apoyo. Un hecho clave en estos cambios de posturas fue la llegada al país de Fidel Castro, en mayo de 1959, para participar de una reunión de la Organización de Estados Americanos (OEA) y entrevistarse con el presidente A. Frondizi. Según las crónicas del momento y los testimonios, Castro "peronizó" parte de su vista al tomar contacto con figuras del peronismo resistente y priorizar recorrer el barrio popular de La Boca por sobre actividades oficiales.

\footnotetext{
8 Ver reconstrucciones clásicas de Fernando Mires (2011) y Marifeli Pérez-Stable (1998).

9 Explica el testimonio de C. Banegas, miembro de la generación fundadora de la JP, ante la emergencia del proceso cubano: "Cuando se viene el tema de la Revolución Cubana, para mí y para muchos de nosotros, al principio no lo veíamos con simpatía. Porque nosotros, como nos faltaba capacitación teórica, nos manejábamos con analogías. Entonces si Perón era el tirano y Aramburu y Rojas eran los libertadores y Batista era el tirano y Fidel el libertador. Entonces, Fidel debe ser el tirano. Pero después las cosas no son así y además empezamos a tener cierta ingerencia de estos compañeros universitarios de izquierda (...) Entonces esos contactos nos empezaron a dar alguna otra serie de elementos. No sólo de charlas orgánicas, sino de charlas y conversaciones en general". Entrevista a Banegas, Carlos por el autor, La Plata, 20 de agosto de 2006 y 7 de marzo de 2007.
} 
Pis Diez y Robles. Radicalización política y represión estatal: la juventud obrera y universitaria ante la Revolución...

No obstante, como dijimos, el apoyo de los jóvenes peronistas al proceso cubano no va a ser inmediato. Quizás porque la política latinoamericana no siempre se entremezcla con la nacional de forma automática, menos con la local. La JP platense iban a encontrar una ocasión para criticar a sus pares de la universidad con la emergencia del Movimiento 14 de Mayo, una guerrilla paraguaya que buscaba derrocar al gobierno de Alfredo Stroesner, rápidamente emparentado con el M26 cubano y, en La Plata, apoyado por el movimiento estudiantil en sus distintas variantes. En respuesta a estos posicionamientos, la JP hará una irónica crítica al trato que recibían los guerrilleros paraguayos, denominados por la prensa local "jóvenes revolucionarios que lucha por la libertad del pueblo guaraní'”. Es que al mismo tiempo, desde mediados de 1959 operaba en el norte argentino la guerrilla peronista Uturuncos, también con inspiración cubana y con el objetivo de lograr el regreso del líder exiliado. En la misma nota, los jóvenes peronistas denunciaban la hipocresía de las lecturas, pues no había periódico donde Uturuncos no fuera calificada bajo los motes de delincuencia y terrorismo. ${ }^{10}$

Iniciado el año 1960, Cuba va a constituirse en una suerte de tema "parteaguas" en la Universidad de La Plata. El consenso inicial entre estudiantes, profesores y autoridades se disolvió casi al mismo tiempo que la isla radicalizaba sus posturas hacia el modelo socialista. A partir de aquí una parte del estudiantado, la reformista de izquierdas profundizó su apoyo a Cuba, ganándose la oposición de sectores universitarios anti comunistas, cristianos y reformistas más bien liberales. En cuanto a la JP, debemos decir que el apoyo se mantuvo en el mismo nivel de ambigüedad hasta 1961, esto es, no se profundizó aunque tampoco se abandonó. Como veremos, entre marzo y septiembre de 1960, buena parte de la dirigencia de la JP había sido encarcelada, quedando la organización prácticamente inactiva. Más allá de las lecturas comunes respecto de Cuba y su influencia sobre la juventud, el caso de la JP platense nos otorga elementos empíricos para pensar tal impacto basados en un caso concreto.

A mediados del año 1960, con el auspicio de la FULP y diversos Centros de Estudiantes latinoamericanos, comienza la convocatoria para participar en el Primer Congreso Latinoamericano de Juventudes, a realizarse en La Habana el 26 de julio. Buena parte de las organizaciones estudiantiles de izquierda anunciaron su participación en el Congreso. El apoyo a Cuba además tomó forma de Comisiones de Solidaridad creadas en Facultades como las de Derecho, Económicas y Humanidades. En marzo de 1960 el Centro de Estudiantes de la última, organizó una charla con Jorge Masetti, anunciado como director de Prensa Latina, agencia de noticias latinoamericana recientemente creada en Cuba. Como contraste, la convocatoria a La Habana suscitó reacciones encontradas entre los jóvenes peronistas. La JP platense no asistió ni logró manifestarse al respecto. El silencio fue ocupado por la JP de Ciudad de Buenos Aires que emitió un comunicado, que los diarios platenses replicarían, informando la no concurrencia al Congreso "por considerar que en su seno prevalecen elementos de neta tendencia comunista". ${ }^{11}$

\footnotetext{
${ }^{10}$ Seguimos la crónica en El Argentino, La Plata, notas varias de 21 de diciembre de 1959 y 28 de enero de 1960.

11 "La JP no ha de asistir a un Congreso en La Habana", El Argentino, La Plata, 20 de julio de 1960.
} 
En enero de 1961, la ruptura diplomática de los Estados Unidos con la isla fue duramente criticada por la FULP en un comunicado que, haciendo uso de las frases emitidas en la Primera Declaración de La Habana, la calificaba como una nueva maniobra imperialista contra el pueblo cubano:

"Hermanos guajiros que están siendo asediados y cercados continua y pertinazmente por las garras imperiales; su culpa es haber roto las cadenas de oprobio y de esclavitud; su delito es decir al mundo [...] que condena a los gobiernos que desoyen el sentimiento de sus pueblos para aceptar los mandatos de Washington"12

Al mismo tiempo, surgió con dinamismo la Comisión de Apoyo de la Revolución Cubana de la ciudad, formada por organismos estudiantiles y partidos de izquierda como MIR-Praxis, Palabra Obrera y el Socialismo Argentino. ${ }^{13}$

A comienzos de febrero de 1961, la UNLP inauguró la nueva sede de su Comedor, espacio que se constituyó en la nueva "vidriera" de la dinámica política estudiantil y, más en particular, de las polémicas clave del año: Cuba y el comunismo en la universidad. Al mes de inaugurando el nuevo edificio, las organizaciones cristianas denunciaron a los reformistas y a los comunistas por realizar "propaganda sectaria", esto es, colocar carteles alusivos a Fidel Castro y mensajes que ridiculizaban al mundo católico y a los Estados Unidos. Lo que es un episodio típico de la vida estudiantil, las trifulcas por carteles y espacios, adquiere relevancia por su contexto y las lecturas sobre el mismo que comenzaron a imponerse. El apoyo reformista hacia Cuba se redobló luego de la invasión a Bahía Cochinos en abril y mayo de 1961 así como también lo hizo la actividad del complejo de fuerzas anticomunistas en Argentina y el continente. Fuerzas Armadas, servicios de inteligencia, actores políticos de diversa tendencia, sectores del clero y de la prensa, llevaron al límite su anticomunismo reclamando al gobierno la ruptura con Cuba y medidas de represión contra la izquierda, el peronismo combativo y los grupos universitarios pro cubanos catalogados, sin grises, de "subversión castrista y comunista" (Bozza, 2016, p. 10).

La cuestión no quedaba solo en el plano de las declaraciones y la prensa escrita. A mediados de abril de 1961, las acciones de apoyo a Cuba frente a la invasión de Bahía Cochinos, tuvieron como resultados numerosas detenciones y enfrentamientos callejeros, con la policía y grupos anticomunistas. Para fines de mes, la FULP convocó a un acto en defensa de Fidel Castro y la Revolución Cubana en conjunto con la Comisión de Apoyo y otras organizaciones de la ciudad. Las cosas no habían comenzado bien

\footnotetext{
12 “Declaración de FULP”, El Argentino, La Plata, 6 de enero de 1961.

${ }^{13}$ No es casual la mención a estas organizaciones pues ninguna de ellas tenía una postura antiperonista. Incluso, el accionar sindical de Palabra Obrera se realizaba en gremios identificados con el peronismo. En una entrevista, Carlos Banegas afirma que los jóvenes de la JP reconocían "la sensibilidad popular y nacionalista de los socialistas, en contraste con el internacionalismo comunista". Recuerda también la fuerte identificación política y personal que tendrán con los dirigentes locales de Palabra Obrera. Entrevista a Banegas, Carlos por el autor, La Plata, 20 de agosto de 2006 y 7 de marzo de 2007.
} 
Pis Diez y Robles. Radicalización política y represión estatal: la juventud obrera y universitaria ante la Revolución...

cuando las autoridades de la UNLP, considerando que "las circunstancias especiales imperantes configuran un ambiente de tensión propicio a los excesos", no autorizaron el uso del edificio central. Luego, la misma mañana del acto quedó claro el clima que iba a marcar el día. En el comedor, que había amanecido con dos banderas que colgaban de sus paredes exigiendo "Libertad a los compañeros" y "Cuba sí, yanquis no", un grupo de estudiantes que invitaba al acto acabó a los gritos con otro de signo contrario. Llegó la policía y la situación se desmadró: los estudiantes le arrojaron palos y cascotes y aquella respondió con bombas de gases lacrimógenos y chorros de agua. A las tres de la tarde finalizó la batahola, con importantes destrozos, cuatro heridos y once detenidos. El acto finalmente se realizó frente al edificio de la UNLP pero al finalizar hubo enfrentamientos con grupos anti comunistas, con golpes, palos e incluso armas de fuego. Llegó la policía, arrojó gases y los grupos se dispersaron. Esta vez, los detenidos sobrepasaron los 40. ${ }^{14}$ En las páginas de los periódicos, las declaraciones y denuncias hacia la "infiltración marxista" en la universidad eran casi cotidianas.

No es difícil observar en la crónica de sucesos la escalada de violencia que marcó la primera mitad de 1961. Más allá de los hechos, varias cosas podemos decir al respecto. La primera es que Cuba radicalizó a las izquierdas, universitarias y políticas, pero también logró tal efecto con las fuerzas policiales, los sectores de derecha, nacionalistas y anticomunistas de la ciudad. El impacto de la Revolución en tales fuerzas se tradujo en una ofensiva represiva, con persecuciones, detenciones y atentados sobre los grupos de izquierda cubanistas en la Universidad. Realmente, y un seguimiento cotidiano de los periódicos nos lo muestra, era difícil abstraerse de este clima de "guerra fría” en la universidad y al interior del mapa estudiantil (Pis Diez, 2018). Es en este contexto que la JP se pronuncia, por primera vez, con fuerte énfasis sobre los sucesos de Cuba, apoyando al gobierno caribeño y denunciando la intromisión estadounidense con las siguientes palabras:

“Ayer fueron Puerto Rico, Guatemala y muchos países más de África y Asia, y hoy es Cuba quien sufre la invasión cruenta del imperialismo yanqui, que no se detiene ante nada en su insaciable sed de dominio. La JP de La Plata fiel a los principios del peronismo, que considera el principio de las nacionalidades como sagrado [...] repudia en la forma más enérgica la invasión de que es objeto Cuba". ${ }^{15}$

\footnotetext{
${ }^{14}$ La crónica la encontramos en El Argentino en las notas: "Produjerónse ayer diversos incidentes durante actos de adhesión a Fidel Castro", "Hubo violentos incidentes en la zona céntrica de nuestra ciudad", "Fueron promovidos por grupos estudiantiles", El Argentino, La Plata, 22 de abril de 1961.

15 "Repudian severamente la invasión a Cuba, grupos ideológicos diversos", El Argentino, La Plata, 20 de abril de 1961. En este marco, la FULP realizó un expreso pedido a la CGT local para que manifestase su apoyo al proceso cubano. La central obrera, para tratar el pedido, organizó un multitudinario y significativo debate, que tuvo como resultado una declaración un tanto ambigua. Si bien la misma repudiaba la invasión a la isla y solicitaba la libertad de los estudiantes detenidos, el pedido de la FULP de apoyo conjunto obrero estudiantil a la revolución, fue objetado. Una crítica al movimiento estudiantil por su lugar en 1955, se completaba con la evaluación negativa del proceso cubano en la medida en que había permitido el avance el comunismo. Si bien no tenemos conocimiento de la participación de la JP
} 
Bajo esta dinámica de los acontecimientos, los jóvenes peronistas fueron dando forma a una interpretación particular sobre el proceso cubano que no supuso un apoyo inmediato. En primer lugar, pasaron de la crítica al apoyo tibio al mismo tiempo que Cuba pasó ubicarse en una u otra posición en la dicotomía nacional antiperonismo/peronismo. Segundo, cabe decir que mantuvieron siempre la impugnación al actor universitario y de izquierda por apoyar un proceso y no otro (el peronista), entendidos ambos como luchas populares y nacionalistas. Luego, ya en 1961, fueron contundentes al evaluar a Cuba como un caso de lucha popular por la autonomía nacional. Desde un antiimperialismo en clave tercermundista, antes que desde el apoyo al modelo comunista, fue como la juventud obrera peronista de La Plata acabó defendiendo a Cuba. Esto, a diferencia de los jóvenes universitarios, en buena medida identificados con diversas organizaciones de izquierda que apoyaron la gesta desde su inicio, e incluso saludaron su acercamiento al modelo socialista.

\section{La represión estatal $y$ el movimiento juvenil platense: acercamiento y radicalidad política}

En principio y durante el primer tramo de su gobierno, Arturo Frondizi tomó una serie de medidas que cumplían buena parte del programa hacia el movimiento obrero, entre ellas, una amplia amnistía que mermó los conflictos estrictamente obreros durante los primeros meses de 1958. Sin embargo, la segunda mitad del año y todo 1959 van a estar marcados por importantes conflictos en torno a la privatización de ámbitos estatales que, en el lenguaje de la época fue leído como "entrega" de las empresas nacionales, el petróleo y la educación. En este marco, a fines de 1958, se presentó un plan de estabilización económico, condicionado a un acuerdo con el Fondo Monetario Internacional, que abarcaba medidas de ajuste, como una fuerte devaluación o la "reestructuración" de la administración y las empresas estatales (que incluía la posibilidad de privatizarlas). De su aplicación no podía sino derivarse un aumento de la protesta social, particularmente, en los sectores "reestructurados", ferroviarios, bancarios, petroleros (Schneider. 2005; Belini y Korol, 2012). Así, la aplicación de tales políticas estuvo acompañada por la intensificación de la represión y el anticomunismo. A partir del año 1959, se sucede la sanción de decretos y leyes que enfocaban el problema de la seguridad en clave de guerra interna antisubversiva. En marzo de 1960 es puesto en vigencia el más conocido Plan CONINTES, que colocaba la seguridad interna en manos de las Fuerzas Armadas. ${ }^{16}$ El plan consistía en delimitar un espacio territorial bajo amenaza de un "enemigo interno" y por ello, definido como zona de

en dicho plenario, cabe el comentario sobre cómo lo trataron otros espacios del peronismo. "Repudió el plenario de la CGT local el avasallamiento al pueblo cubano", El Argentino, La Plata, 22 de abril de 1961.

${ }^{16}$ La aplicación del Plan CONINTES (Conmoción Interna del Estado) estuvo basada en una ley promulgada por el gobierno peronista que establecía la organización de la población para los tiempos de guerra. Puede afirmarse que la implementación que hizo el frondizismo de esa legislación dio forma a un verdadera "estado de excepción" o "momento en que el derecho suspende al derecho para garantizar su continuidad" (Agamben. 2005, pp. 5-6). Sobre el Plan CONINTES puede verse Pontoriero (2015) y Barbero y Godoy (2003). 
Pis Diez y Robles. Radicalización política y represión estatal: la juventud obrera y universitaria ante la Revolución...

operaciones militares, en la que las Fuerzas Armadas participaban de manera directa en la represión y juzgamiento de la población civil. Bajo esas premisas, a comienzos de 1959, se declararon como zonas militares las localidades de Berisso, Ensenada y la ciudad de La Plata, caracterizadas como estratégics por estar localizadas en esa área la destilería petrolera de YPF, la empresa estatal (AAVV, 2014, p. 50). No era para menos el contexto: entre mediados de 1958 y mediados de 1961 la ciudad de La Plata se encontró atravesada por masivas movilizaciones, enfrentamientos entre organizaciones de izquierda, las más de las veces universitarias, y anticomunistas; la conflictividad obrera además, no hacía sino aumentar. ${ }^{17}$

En el apartado anterior pudimos observar estos elementos más aplicados al mundo estudiantil, cabe ahora enfocarnos en una Juventud Peronista inscripta desde su refundación en aquella dinámica de resistencia que suponía enfrentamientos con personas y grupos identificados con el antiperonismo; acciones directas en apoyo a conflictos sindicales puntuales y acciones que parecían formar parte de una estrategia insurreccional atribuida a directivas de Perón. ${ }^{18}$ En términos concretos, el inicio oficial del Plan CONINTES en la ciudad de La Plata fue en marzo de 1960 y tuvo como notas centrales las detenciones de importantes miembros de la JP, a quienes se les atribuyeron participación en aquel complejo de acciones directas.

En julio de 1960, se hizo público el Informe oficial de las autoridades del CONINTES sobre la represión en la zona de La Plata. En particular, describía la estructura militante de la JP cuya dirigencia había sido detenida. El jefe del grupo, Eduardo Juan Leguizamón, era un suboficial de Marina que oficiaba de enlace con células regionales articuladas con organizaciones y dirigentes nacionales del peronismo resistente. El núcleo del entramado local, según el mismo informe, era la comisión directiva del gremio ATE, conformada por miembros de la JP como Práxedes Molina y Haroldo Logiurato. Desde mediados de 1959, esta organización recibía materiales explosivos para distribuir, tarea que se le atribuía a su secretario administrativo, P. Molina (Rot, 2016, p. 53). El informe asegura que el propio secretario general de ATE, Logiurato, tenía en su poder un "plan de resistencia civil" de once hojas con membrete de la CGT, que caracterizaba a la Argentina como ocupada por una fuerza enemiga y se proponía crear un clima propicio para la vuelta de Perón. Recordemos que ATE era uno de los

\footnotetext{
${ }^{17}$ Según el balance oficial, dado en el momento en que se anunciaba el levantamiento del plan en agosto de 1961, los números finales daban una clara idea de la magnitud que alcanzó el accionar de los sectores radicalizados en pugna. Entre el 1/5/58 y el 30/6/61, y en un plano nacional, se colocaron 1022 bombas, los atentados llegaron a 1566 y el número de muertos y heridos se elevó a 17 y 89 respectivamente. "Refuta la CGT local el informe CONINTES", El Argentino, La Plata, 2 de agosto de 1961.

${ }^{18}$ En agosto de 1958 estalló una bomba en un restaurante en las calles 51 y 17 donde estaba reunido un grupo de 20 personas miembros del antiperonista Partido Cívico Revolucionario. Luego, en el contexto del paro nacional por la privatización del frigorífico Lisandro de la Torre (enero de 1959), en la ciudad de La Plata, estallaron una serie de bombas en diferentes fábricas. Por último, ya a comienzos de 1958, el jefe de la policía de la provincia, había denunciado la existencia de una "organización terrorista" con sede en La Plata, compuesta por 710 hombres y mujeres. Según el comunicado policial operaba con instrucción de Perón y tenían como tarea central realizar atentados sobre vías de comunicación y abastecimiento de combustibles.
} 
espacios sindicales donde mayor peso tenía la JP y una de las referencias del peronismo sindical combativo en la ciudad. ${ }^{19}$ Desde allí, partían vínculos con el sindicalismo local y la CGT platense, cuyo secretario general Segundo B. Palma se encontraba prófugo junto con otros miembros de la JP como Diego Miranda, Clemente Saavedra, Roberto Mario Carattoli y Juan José Bartoletti. Finalmente, el informe mencionaba una serie de dirigentes peronistas locales pertenecientes a la generación anterior muy influyentes y valorados por los jóvenes como Horacio Chaves y Rolando Nhatiuk, entre otros. ${ }^{20}$

El Informe coincidió con el fuerte impacto que tuvieron los procedimientos de detención de los jóvenes peronistas platenses. Entre las primeras reacciones se cuenta la prolongada y sistemática campaña que inició la CGT, en favor de los jóvenes denominados "presos Conintes". Se realizaron publicaciones en los diarios locales denunciando que los procedimientos de detención se hicieron "cometiendo todo clase de desmanes no sólo contra los dirigentes gremiales sino también contra los hogares, tomados por asalto en horas de la madrugada". ${ }^{21}$ Paralelamente, los abogados de la CGT Pedro Michelini y Carlos Bruza lanzaron una amplia actividad defensista con la presentación de recursos de habeas corpus ante la Justicia Federal. El organismo respondió desconocer la existencia de los detenidos, motivando a los letrados platenses a denunciar públicamente el "secuestro" de sus patrocinados y establecer un precedente sobre la condición de los detenidos por razones políticas. Desde el ámbito de los familiares, y siempre con el apoyo de la CGT, se creó a comienzos de abril de 1961, la Comisión de Damas (luego de Familiares) destinada a solventar los gastos de los familiares de los detenidos afectados económicamente por los encarcelamientos haciendo pedidos de colaboración financiera a la comunidad platense. Este grupo de familiares se fue consolidando, obteniendo recursos para el traslado y el alojamiento en las visitas a las cárceles, también apoyo jurídico y médico, gracias a la incorporación de miembros del Partido Comunista local. Una dimensión de las políticas represivas que unificó las críticas, presente en la declaración anterior y denunciada tempranamente por la Comisión de Familiares ${ }^{22}$, fue la metodología de las torturas. En

\footnotetext{
${ }^{19}$ Dice P. Molina sobre tales cuestiones: "Nosotros recuperamos ATE en 1958. Se hicieron elecciones y pasé a integrar la comisión directiva de la seccional La Plata. Desde la JP y el gremio tuvimos una presencia muy importante en la lucha callejera y en muchos paros, a veces nacionales. Como el famoso paro del frigorífico Lisandro de la Torre. Estas fueron las primeras tareas de acción directa de la JP, una gimnasia y una preparación. El caso del frigorífico Lisandro de la Torre fue muy importante porque fue la primera ocupación de una fábrica. Acá en La Plata el paro duró 5 días [...] Nosotros seguimos en el gremio hasta 1960. En el 60 con la vigencia del Plan Conintes y la profundización de toda esta lucha, trajo como consecuencia que nosotros sumáramos experiencia y habíamos cometido el terrible error de comenzar a leer otros cosas y a enterarnos de los que pasaba en el mundo. La revolución cubana había empezado a tener efectos muy importantes [...] Me meten preso, junto con otros 40 o 50 dirigentes sindicales y de la JP el 27 o 28 de marzo." Entrevista a Molina, Práxedes "Babi”, por el autor, La Plata, 5 de junio de 2005.

20 "El ex general Iñiguez era el que cumplía órdenes de Perón”, El Argentino, La Plata, 30 de julio de 1960.

21 "Fueron detenidos otros dirigentes", El Argentino, La Plata, 30 de marzo de 1960.

${ }^{22}$ La Comisión, había gestionado un contacto entre los jóvenes detenidos y el obispo de la ciudad, Monseñor Plaza, que fue negado por las autoridades militares. Al respecto, declaró que el encuentro fallido se debió al "estado calamitoso en el que se encontraban como consecuencia de las torturas a las que fueron sometidas en esa dependencia militar". "Censura un organismo juvenil del peronismo al Episcopado Argentino", El Argentino, La Plata, 6 de diciembre de 1961. Ver también Chama (2014).
} 
Pis Diez y Robles. Radicalización política y represión estatal: la juventud obrera y universitaria ante la Revolución...

efecto, la instalación pública de las torturas, las condiciones de encarcelamiento y el status de los detenidos será un eje de acción conjunta contra el CONINTES. Para los jóvenes de la JP detenidos será una oportunidad de interpelación al conjunto del movimiento juvenil y político en general. ${ }^{23}$

Es que la escalada represiva gubernamental también alcanzaba al espacio estudiantil. A mediados de 1960, la FULP impulso una serie de iniciativas en línea con el activismo a favor de los jóvenes, convocando a una Mesa Redonda sobre "libertades públicas y represión" participando, entre otros, a la CGT platense y expresando su rechazo a la situación social por los medios locales:

"El país vive un momento de grave convulsión: la situación económica que sufre la mayor parte de la población, que es la que está sobrellevando el Plan de Austeridad con que se pretende levantar la República, provoca una situación inestable. El pueblo sabe que todos los sacrificios los están realizando los sectores más desposeídos". ${ }^{24}$

La ola de discriminación, denuncias y detenciones sobre los jóvenes de izquierda; así como también la represión policial frente a diversas movilizaciones, en Medicina, en el Comedor y en las calles platenses en apoyo a Cuba; o los atentados perpetrados por organizaciones anticomunistas hacia los Centros de Estudiantes reformistas, nos hablan del ataque hacia el reformismo de izquierdas, la otra cara de la represión en la ciudad. En abril de ese año un comunicado de FULP intenta ilustrar la situación vivida por la militancia estudiantil:

"La FULP denuncia una vez más otro atropello y la ola represiva desatada contra el movimiento estudiantil (...) Decenas de compañeros presos, dirigentes estudiantiles con captura recomendada. Cualquier pretexto es bueno. Detenidos en sus casas, detenidos en las calles, detenidos en los jardines de la Universidad, detenidos y corridos en el edificio mismo de la Facultad de Ingeniería”25.

En las lecturas estudiantiles, las denuncias hacia la política represiva de Frondizi empalmaron muy fácilmente con las críticas a las posiciones exteriores de nuestro país, los ataques a la Revolución Cubana y la nueva ofensiva norteamericana sobre América Latina. De acuerdo a esto, la lucha excedía los márgenes de una universidad atacada

${ }^{23}$ Acción que tendrá sus frutos. Por ejemplo, en el Concejo Deliberante platense se aprobó la iniciativa del Partido Socialista Argentino para solicitar al Congreso Nacional la derogación del CONINTES por inconstitucional. "Plan Conintes: Manifesta el Colegio de Abogados que es inconstitucional", El Argentino, La Plata, 10 de mayo de 1960.

24 "Fustiga FULP al Gobierno por aumento en las Fuerzas Armadas", El Argentino, La Plata, 31 de agosto de 1960.

25 “La FULP denuncia y advierte", abril de 1961, Documento Federación Universitaria de La Plata, Leg.1. Factor A. Mesa Estudiantil. La Plata. Fondo DIPBA-CPM. 
en su autonomía por los mismos actores que igualmente avasallaban las libertades del movimiento obrero o los avances sociales de la isla caribeña. ${ }^{26}$ En este marco, no fueron pocos los casos en que la FULP intentó buscar aliados entre los sindicatos agrupados en la CGT local. Así, en agosto de 1961, la dirigencia de la entidad obrera realizó gestiones frente a la CGT nacional y al Ministro de Gobierno bonaerense solicitando la libertad de estudiantes detenidos, haciéndolo "con la autoridad de quien ha sido también perseguido por el desgobierno, pagando como tributo [...] las libertades de compañeros trabajadores que después de torturados padecen injusta cárcel por imperio de la aberración Conintes". ${ }^{27}$ No olvidemos que, en la misión contrarrevolucionaria asumida por los militares, el enemigo interno era múltiple y estaba en espacios diversos. La guerra contra el comunismo era considerada una "cruzada contra el totalitarismo" en la cual militantes de izquierda y peronistas eran, por igual, objetivo de la acción represiva.

Pero las lecturas de los actores sobre el Plan CONINTES y la represión no eran siempre coincidentes. No lo iban a ser entre sindicalistas y estudiantes, tampoco entre sindicalistas y jóvenes peronistas. A mediados de 1960, en la Cámara de Diputados de la Nación fue creada una Comisión Investigadora de Supuestos Apremios Ilegales, el marco de garantías institucional mínimas para que las denuncias hacia la represión comenzaran (AAVV, 2014, p. 128). Entre los testimonio más trascendentes estuvieron los de los jóvenes miembros de JP platense Haroldo Logiurato, Diego Miranda y Juan José Bartoletti. Particularmente Logiurato, desde la cárcel, presentó un verdadero alegato militante contra las torturas y el plan CONINTES. Efectuado en junio de 1961 su alegato buscaba alertar sobre el carácter sistemático de la tortura como medio de obtención de información. Esta visión sistemática del plan represivo era discordante con la del grupo de abogados de la CGT y muchos sectores del propio peronismo local, para quienes la responsabilidad de las torturas recaía en un pequeño grupo de policías, salvando a la mayoría de las fuerzas represivas. Contrariamente, para los jóvenes, el Plan CONINTES era una muestra de las características de las Fuerzas Armadas y la importancia de no contemplarlas como aliadas.

En junio de 1960, tuvo lugar el traslado de los presos de la JP al presidio de Ushuaia. ${ }^{28}$ Las condiciones carcelarias extremas se convirtieron a partir de entonces en un eje de denuncias, no solo de los peronistas, también de otras fuerzas de izquierda. ${ }^{29}$

\footnotetext{
${ }^{26}$ Continúa el comunicado:"Quienes la atacan (a la universidad) son los mismos que denuestan y denigran al heroico pueblo cubano [...] La FULP no dará tregua a los capataces de los intereses imperialistas. Nos encontrarán en el terreno que elijan. Defendemos a la Patria defendiendo a Cuba revolucionaria [...] defenderemos a toda costa nuestras libertades, que son las libertades del pueblo argentino". "La FULP denuncia y advierte", abril de 1961, Documento Federación Universitaria de La Plata, Leg.1. Factor A. Mesa Estudiantil. La Plata. (Fondo DIPBA-CPM).

27 "Pedido de la FULP a la CGT local", El Argentino, La Plata, 25 de agosto de 1961.

28 "Sobre el traslado de dirigentes a Ushuaia dio un comunicado la CGT", El Argentino, La Plata, 18 de junio de 1960. La CGT en un comunicado informó que entre los trasladados estaban los cinco dirigentes gremiales platenses ligados a la juventud: Haroldo Logiurato, Babi Práxedes Molina, Héctor Enrique Gaite, Horacio Jacinto Cassano y Antonio Wenceslao Lombardi.

${ }^{29}$ También la Liga Argentina por los Derechos del Hombre, ligada al PC, vistió el penal y brindó una conferencia de prensa donde denunció las condiciones de los "presos CONINTES" (Rot, 2016, p. 54).
} 
Pis Diez y Robles. Radicalización política y represión estatal: la juventud obrera y universitaria ante la Revolución...

Esto impactó en el escenario platense, donde las denuncias cobraron fuerte impulso desde la CGT, entidad que convocó a detener "la máquina represiva de las torturas"; y desde el amplio dispositivo de familiares y organizaciones políticas que iniciaron la lucha por mejorar las condiciones de detención de los jóvenes. Varios hechos contribuyeron al logro del traslado de los presos a cárceles con mejores condiciones: las denuncias y presiones sobre las Comisiones Investigadoras sobre la Tortura, una huelga de hambre de casi cincuenta presos y la consolidación de la Comisión de Familiares de Detenidos (COFADE) y de su filial platense a mediados de 1961. A partir de aquí, no solo se logró una paulatina mejora de las condiciones de detención sino que también se conformó una red de ayuda que comenzó a proveer recursos materiales así como también nuevos canales e interlocutores para el debate político. Por último, los testimonios destacan que las condiciones de encierro más flexibles permitieron establecer contactos, intercambios y debates entre la variada militancia presa. Los jóvenes peronistas tuvieron posibilidad de encontrarse con miembros de la JP Capital como Jorge Rulli, de la guerrilla filoperonista de los Uturuncos y de importantes dirigentes provenientes de otros centros políticos, como los marplatenses Dionisio Pereyra y Norberto Centeno. También, con importantes figuras del Partido Comunista como Jacobo Perelman y Emiliano González, con quienes se abrió un importante debate sobre la cuestión cubana, ya que ambos eran miembros directivos de la Comisión de Solidaridad con Cuba.

Como balance de toda la experiencia represiva y carcelaria de los CONINTES hay que decir, primero, que algunos sectores del peronismo la evaluaron de manera muy endogámica, siendo reticentes a la colaboración de espacios políticos con una larga experiencia en la ayuda a sus presos como el PC. Sin embargo, para los jóvenes de la JP platense implicó una importante acumulación de capital militante que sirvió para construir y liderar una identidad claramente revolucionaria y de izquierda para el peronismo. ${ }^{30}$ En un plano externo, se fortalecieron los vínculos con sectores del movimiento estudiantil de izquierda, con el cual, no sin desavenencias, buscó establecer estrategias conjuntas.

\section{Algunas conclusiones}

El trabajo que hemos presentado se ha enfocado en dos actores centrales del movimiento juvenil platense de comienzos de la década de 1960, la Juventud Peronista y el movimiento universitario reformista de izquierda. Ambos atravesaron diversos procesos al calor de acontecimientos nacionales y continentales, con una dinámica común que definimos de "apertura" y "retroceso". Si el "retroceso" nos remite a los efectos de las prácticas represivas gubernamentales, la "apertura" nos permite observar coincidencias iniciales y coordinaciones concretas, entre dos tipos de organizaciones, en principio, enfrentadas a razón de sus posiciones frente a la política nacional.

\footnotetext{
${ }^{30}$ Cuenta Gonzalo Chaves, segunda generación de la JP platense y futuro miembro de la organización Montoneros: "Cuando salieron en libertad en 1963, Diego Miranda y Haroldo Logiurato, nosotros éramos los más "chicos" pero no era un problema de edad, algunos del grupo teníamos la misma cantidad años. Estos hombre (para nosotros) eran mitos vivientes, jóvenes probados que habían pasado por la tortura y la cárcel, manteniéndose lúcidos y firmes" (Chaves, 2015, p. 78).
} 
Es cierto que, rápidamente, los jóvenes estudiantes reformistas elaboraron una visión crítica sobre los alcances ideológicos y políticos del antiperonismo y que, también con la misma celeridad, los jóvenes de la JP hicieron lo propio con la dirigencia y estructura organizativa del peronismo. Durante el período analizado, ambos actores pasaron por un proceso que acercó sus estrategias y los fue agrupando en un campo político común. Y si bien el apoyo a Cuba no fue inmediato por parte de los jóvenes peronistas, con el correr del tiempo fue aquella una experiencia a reivindicar. Un corolario fue que en 1963 dos miembros de la JP platense viajarán a la isla como parte de un programa de entrenamiento político. Por otra parte, para los universitarios, y una fracción muy amplia de la izquierda argentina, Cuba impulsó una reinterpretación del fenómeno peronista en términos de un proceso nacional y revolucionario.

Por su parte, las políticas de represión estatal implementadas por el gobierno de A. Frondizi lograron desarticular el activismo de los jóvenes. Ambas organizaciones entraron así en un momento de "retroceso": muchos de ellos fueron encarcelados por períodos prolongados, otros torturados y una gran mayoría dispersados. No obstante, y en gran medida como respuesta a lo anterior, ambos actores se radicalizaron. Los jóvenes trabajadores de la JP empezaron asumir prácticas y formas organizativas nuevas, al tiempo que se mantuvieron expectantes en torno a nuevas concepciones políticas que pudieran impulsar revolucionariamente al peronismo. Por su parte, los sectores de izquierda del movimiento estudiantil politizaron y radicalizaron fuertemente su activismo, en la medida en que dieron forma a un programa político que excedía las reivindicaciones universitarias y que incluía una nueva lectura sobre el peronismo, como aliado de la causa revolucionaria con la que se identificaban. No es esta, sin embargo, una historia de linealidades. Muchas cosas ocurrirán en el país luego de 1962. No obstante, creemos que esta reconstrucción empírica ha servido para observar, a través de un foco local y con más matices que generalidades, procesos (como Cuba y la represión anticomunista) que marcaron un período importante de la historia de América Latina.

\section{Agradecimientos}

Este artículo es resultado de la investigación realizada en el marco del proyecto "Las formas y los sentidos de la política y la militancia: la nueva izquierda argentina en los años '60 y '70" radicado en el Instituto de Investigación en Humanidades y Ciencias Sociales de la UNLP. Una primera versión de este trabajo fue presentada en las X Jornadas de Sociología de la UNLP, en la Mesa $\mathrm{N}^{\circ} 10$. Agradecemos todos los aportes y comentarios recibidos en esas instancias.

\section{Referencias Bibliográficas}

Acha, O. (2011) Los muchachos peronistas. Orígenes olvidados de la Juventud Peronista (1945-1955). Buenos Aires: Planeta. 
Pis Diez y Robles. Radicalización política y represión estatal: la juventud obrera y universitaria ante la Revolución...

Agamben, G. (2004) Estado de excepción. Buenos Aires: Adriana Hidalgo editora.

Águila, G. (2015) "Las escalas de análisis en los estudios sobre el pasado reciente: a modo de introducción”. Avances del Cesor, 12, pp. 91-96.

Altamirano, C. (2001) Bajo el signo de las masas. Buenos Aires: Ariel.

AAVV. (2014) Plan Conintes. Represión política y sindical. Buenos Aires: Área de Publicaciones, Secretaría de Derechos Humanos del Ministerio de Justicia y Derechos Humanos de la Nación.

Barbero, H. y Godoy, G. (2003) La configuración del enemigo interno como parte del esquema represivo argentino. Décadas de 1950-1960. Buenos Aires: Cuadernos del CCC.

Bartolucci, M. y Favero, B. (2018) "Historia de la juventud en el siglo XX: aportes metodológicos e historiográficos para su estudio". Pasado Abierto, 7, pp. 2-8.

Belini, Claudio y Korol, J. C. (2012) Historia económica de la Argentina en el siglo XX, Buenos Aires: Siglo XXI.

Bozza, A. (2014) "La resignificación revolucionaria del peronismo y sus protagonistas durante la etapa de proscripción”. En Tortti, M. C. (dir) La nueva izquierda argentina (1955-1976): socialismo, peronismo y revolución. Rosario: Prohistoria.

Bozza, A. (2016) "A la sombra de la Revolución Cubana. Anticomunismo y nueva izquierda en la Argentina de los sesenta". En IX Jornadas de Sociología de la UNLP, 2016, La Plata, Argentina.

Buchbinder, P. (2005) Historia de las universidades argentinas. Buenos Aires: Sudamericana.

Califa, J. (2014) Reforma y Revolución. La radicalización política del movimiento estudiantil de la UBA, 1943-1966. Buenos Aires: Eudeba.

CEPAL. (2005) Boletín demográfico. América Latina: urbanización y evolución de la población urbana (1950-2000). Santiago de Chile: CEPAL/ONU.

Cuchetti, H. (2010) Combatientes de Perón, herederos de Cristo. Peronismo, religión secular y organizaciones de cuadros. Buenos Aires: Prometeo.

Chama, M. (2014) "Activismo social, militancia política y radicalización en los años sesenta: la experiencia de la Comisión de Familiares de Detenidos (COFADE)". En Tortti, M. C. (dir.) La nueva izquierda argentina (1955-1976). Socialismo, peronismo y revolución. Rosario: Prometeo.

Chaves, G. (2015) Rebelde acontecer: relatos de la resistencia peronista. Buenos Aires: Colihue.

Fernández, S. (2007) "Los estudios de historia regional y local: de la base territorial a la perspectiva teórico-metodológica”. En Fernández, S. (comp.) Más allá del territorio: la historia regional y local como problema. Discusiones, balances y proyecciones, Rosario: Prohistoria, pp. 31-46.

Hobsbawm, E. (2006) Historia del Siglo XX. Buenos Aires: Crítica.

Leoni, S. (2013). “Treinta años de historiografía política regional”. PolHis 12, pp. 46-53.

Manzano, V. (2017) La era de la juventud en Argentina: cultura, política y sexualidad desde Perón hasta Videla. Buenos Aires: Fondo de Cultura Económica.

Mires, F. (2011) La rebelión permanente. México: Siglo XXI. 
Pérez-Stable, M. (1998) La Revolución Cubana. Madrid: Colibrí.

Pis Diez, N. (2018) Frondizismo, comunismo y "guerra fría" reformista: politización y fragmentación ideológica en la Universidad de La Plata. Archivos de Historia del Movimiento Obrero y la Izquierda, 12, pp. 53-71.

Pontoriero, E. (2015) "Estado de excepción y contrainsurgencia: el plan Conintes y la militarización de la seguridad interna en la Argentina (1958-1962)". Contenciosa, 4.

Robles, H. (2014) "Desamparo y responsabilidad política: la conformación de la Juventud Peronista (JP) platense entre 1955-1958". VIII Jornadas de Sociología, diciembre. La Plata, Argentina.

Rot, G. (2016) Itinerarios Revolucionarios. Eduardo L. Duhalde - Haroldo Logiurato. Buenos Aires: Campana de Palo.

Schneider, A. (2006) Los compañeros. Trabajadores, izquierda y peronismo. 19551973. Buenos Aires: Imago mundi.

Sigal, S. (1991) Intelectuales y poder en la década del sesenta. Buenos Aires: Puntosur. Slipak, D. (2015) Las revistas montoneras: Cómo la organización construyó su identidad a través de sus publicaciones. Buenos Aires: Siglo XXI.

Souto Kustrín, S. (2007) "Juventud, teoría e historia: la formación de un sujeto social y de un objeto de análisis". Historia Actual Online 13, pp. 171-192.

Terán, O. (2013) Nuestros años sesentas. Buenos Aires: Siglo XXI.

Torre, J. C. (1994) “A partir del Cordobazo”. Estudios, 4, pp. 15-24.

\section{Fuentes}

Actas Taquigráficas del Honorable Consejo Superior de la UNLP, 1959, La Plata. Biblioteca Pública de la UNLP.

Diario El Argentino, La Plata (1959-1962).

Diario El Día, La Plata (1964).

Documento "Universidad Nacional de La Plata". Factor A, Mesa Estudiantil. Legajo 20. La Plata. Comisión Provincial por la Memoria (Fondo DIPBA-CPM).

Documento "Federación Universitaria de La Plata". Factor A, Mesa Estudiantil. Legajo 1. La Plata. Comisión Provincial por la Memoria (Fondo DIPBA-CPM).

Entrevista a Molina, Práxedes "Babi", realizada por el autor. La Plata, 5 de junio de 2005.

Entrevista a Banegas, Carlos, realizada por el autor. La Plata, 20 de agosto de 2006 y 7 de marzo de 2007. 
